\title{
Traveling Through the Arts
}

\author{
John Toth, 1999
}

\begin{abstract}
At the beginning of a journey we always, first, take one step away from home. In a foreign land we look for clues that help us better understand the language of the people. We look at their art, the shapes and designs in clothing and architecture looking for connections that reveal meaning. Strangers reveal their messages, each holding a unique perspective. In the stories they tell, each view holds within it a perspective of understanding. When we read a book or see a painting, we move away from our own familiar way of perceiving, seeking a quest through the eyes of another. From the hillside view of van Goghs', "Starry Night", the village looks very small but the sky becomes a universe inviting exploration and imagination. How much you see is up to you. How do we maximize the awareness of what we experience as we move through our journey? Giving time to notice the details and hear the descriptions of his starry sky, van Gogh invites us on a poetic journey of learning and discovery.
\end{abstract}

\section{The close study of an art work is a model for learning.}

The practice I developed as a teaching artist at Lincoln Center Institute and the Museum of Modern Art grew out of a desire to use art work as a focus of study that provides a common experience for viewers to explore their own ideas and experiences. I have been fascinated by the many responses of teachers and parents when they notice a new perspective in their students as they explore and interpret works of art. A work of art has a unique ability to draw a response and truly enliven the senses of the viewer. As such, Marc Chagalls' painting of "I and The Village" gives students permission to explore their own experience of "village" and notice another world that they can relate to. The ideas within an artwork become a world to be in. Activities constructed around concepts and elements within a given art work ask students to investigate choices and draw conclusions relevant to the content and process of the art work under study.

Students, teachers, teaching artists and mentors all become collaborators in the learning process. Together we find connections between the world we know and the art world of ideas and meaning. Exploring together, we create a "safe ground" open to the multiple languages needed to communicate the depth and range of experiences that make up our lives. The dialogue that develops, when a group of people explore a work of art, reveals meaning that is both unique and shared. A learning community emerges in listening to the different perspectives that each person shares. Collaboration is contagious and inspires creative response.

\section{I find ideas move and shift as we look deeper into the art work.}

As an artist, teaching artist and mentor I investigate process. Exploring process makes us think and act. My ability to keep a conversation going by asking skillful questions would often be the difference between seeing an idea grow or fall to the side. Questions can be used as tools for learning about aspects of the lives of the students. The questions that students ask also become an indicator for possibilities in creating activities that are student centered.

Asking someone a question can be an invitation to take that first step in a journey. Cultivating and articulating these questions can open doors that reveal pathways for learners. By calling attention to the 
details of an art work, students can be drawn to see a connection between their own life experiences through what they observe.

In the following pages I will explore "questions" as a tool that reveals systems of beliefs. There will be sketches and notes and lists of activities that come out of the investigation of questions. We have thought about how our method of looking supports good learning practice and connects ideas and learning to multi modes of disciplines.

\section{Asking Questions as a tool}

\section{A PREDICTION OF DIRECTIONS THAT QUESTIONS CAN MOVE}

- 1. Ask open-ended questions that encourage personal response. The personal perspective of children is enacted in a social setting with a certain amount of risk-taking on the part of the respondents. How do you create a supportive environment that allows for the risk taking inherent in self-expression?

What do YOU see in this picture? (There is no "wrong" answer)

What do you see, that makes you say that? (Additional details make sense)

Does any one else have an opinion? (Interaction of ideas)

- 2. Connect children to their own experience. These questions further learning by linking cognition with affect, drawing upon prior experience, verbal, kinesthetic, auditory and other sense memories.

Does this painting remind you of something you have experienced?

Looking at van Gogh's "Starry Night," I asked a 3 year old,

What does the wind sound like?

He, not only blew a loud howling sound, but leaned in to me,

Real close, so I could feel the blow of his "wind" in my face.

Has anyone looked up at the stars at night? What did you See? Feel? Hear?

- 3. Develop a critical perspective that encourages children to voice their own comments while developing an appreciation for the perspectives of others.

How do you ask questions that encourage making sense of opposites?

How do you encourage children to observe similarities and differences?

Could anyone make a new "title" for this work that considers our ideas?

What do you learn from hearing and seeing many different viewpoints?

What are common details shared among comments? (Shared elements)

- 4. Provide scaffolding for children's ability to make connections between concepts, and develop their 
capacity for abstract reasoning in the verbal and non-verbal modes. Consideration of these questions calls for imaginative leaps in thinking and often involves locating commonality where none is apparent and differences where only sameness is immediately visible.

How do you develop abstract reasoning?

How do you construct modal connections of questions between questions?

What is going on in this picture?

Describe who is "looking" in Chagall's "I and The Village"?

Describe the way in which you know the "green man" sees the "animal"?

What does the dotted line suggest? Why two colors? Why red and white?

What does this say about the relationship of these two?

How do they relate to the village?

- 5. Help children develop language for articulating concepts through physicalizing their understanding of the work of art. Here, the connection is to develop activities that extend the learning by linking sensory experience to language. How do you CREATE experience through questions? What kind of questions that expand experience?

What do you learn about Andrew Wythe's, "Christina World" by getting into the pose of Christina?

- 6. Ask children to draw upon their capacity to imagine the unknown. These questions encourage children to consider possibilities, and help them develop an appreciation of and a tolerance for ambiguity. (An appreciation of the unknown ... sensing new associations.)

What would you do if you could enter "Starry Night"?

Selecting a work of art to study is similar to choosing a good book or movie. That is, I want the artwork to contain the makings of a good story. I want the art to have within it, something that can be talked about.

Choosing the art work for a unit of study means less about what I think a good work of art is and more about what I predict the students will respond to. I am trying to avoid the suggestion that I want the students to "like" the art because I am more interested that they find meaning in the art, whether or not they like the art work. What is important to me is that the artwork "triggers" a personal response to an experience they have had. The artwork must have something to do with THEIR life. Often this requires that the work under study has observable details that can that imply meaning that they have experienced: "the swirls in the sky make it seem like the wind is blowing" or "the blue swirls in the sky make it seem like the wind is cold."

The uniqueness of each artist's expression may imply an empathy to the connection: "I have never seen the wind blow like "Starry Night" but I have felt the wind blow like that."

F requently, teachers ask me to show their students paintings by the Impressionists because they want their students to experience the beauty of this work. While there is nothing wrong with this request I struggle with this because I am less interested in beauty and more interested in meaning. Again, it is the personal connections that the work elicits within the students that should be the issue. What is it within the work of 
the Impressionists that would relate to the lives of young students? My question to the teachers is then, "What is it about the impressionists' paintings that interests you?" Is it the act of creating an "impression" that is of interest? Is it the atmospheric quality? Or is it the notion that the artist was viewing subject matter over time? There are "issues" that make impressionism relevant and beautiful; this is where I want to go.

Sequencing the order of art works that we look at allows ideas to unfold. A sequence of art works could be developed to move from simple to complex . Or a sequence may explore a range of choices that different artists explore within a given theme or context.

There is another important consideration, age appropriateness; i.e., selecting artworks that have ideas that are appropriate to the student's experiences. Exploring issues about "time" with young children (3-6) does not make a lot of sense because it is beyond their reasoning.

We are not lecturing on an "ism" but facilitating the understanding of the ideas processes within the art work. I begin with open-ended questions that allow for personal responses and then ask viewers to describe and elaborate on details within the painting that led them to their interpretations. Within these descriptions and interpretations there are often comments that analyze the effect of techniques and compositional choices that draw attention to specific ideas. I use my questions as a tool to encourage students to describe, analyze and interpret a work of art based on details they see. From their stories and the artwork, I see indicators that suggest activities. About Chagall's "I and the Village" a student spoke, "There is a circle in the middle of the painting that seems to unite the man and the goat... and the tree... everything."

Where are indicators that could lead me in many directions. I immediately like the geometry and visual nature of the circle as a structure that creates unity. A simple "notice" activity would be to take a photograph from the newspaper and see what kind of geometric shapes you could impose onto its apparent structure. I could draw thousands of squares, rectangles and triangles as I look across my $3^{\text {rd }}$ floor Brooklyn view of Manhattan.

Knowing that Chagall painted "I And The Village" in Paris from memories of his past life in a $19^{\text {th }}$ century Russian village, I could modify this lesson, asking everyone to draw a scene from a past memory that shows important details of events that occurred at that time, using geometry as a device to organize narrative elements.

\section{Work to Explore:}

Vincent van Gogh, (Dutch, 1853-1890), "Starry Night", 1889

What do you see? Hear? Feel? Think?

What would it look like from the other side of the mountain?

Who lives is the village below?

What does the artist magnify?

How does your eye move through this painting?

Activities can develop connections in thinking by exploring and experimentation of materials. 


\section{Activity comes out of the investigation of questions.}

What kind of activities do the questions provoke?

Do the comments of children suggest an investigation of specific concepts or material use?

Is there anything in the responses that implies an action or reaction that could be an activity?

Do the qualities of expression suggest specific tools, materials or technique?

Within answers are there possibilities of investigations and discovery?

What new questions does the activity provoke?

On questions about "points-of-view", a third grade student posed the question,

"What would van Gogh's village look like from the other side of the mountain?"

Within this question is a request for a journey across a detailed world alive with possibilities.

Write a short story about the people you would meet crossing this painting?

How would you map the energy of the life around you?

How can your drawing account for the repetition of sounds you might hear?

Warm -up: Have students ask questions . Documentors try to create categories.

As a group discuss possibilities for themes and activities.

\section{Some Questions and Thoughts On Traveling Through The Arts}

What are the differences between communicative vs. evocative experience?

How do we keep the artwork preserved and at the center of learning?

What is the dilemma of "Ed speak" versus "art speak"?

How do we explore a work of art?

Is the artwork for me or is it for my students?

How do we ask questions that call for a consideration of others beliefs?

How do we ask questions that reveal personal meaning?

What do you see in this picture?

Is it our goal to bring people to consider the internal?

What do we do with contrary beliefs?

How do we compare consensus to unique perspectives? 
If the artwork is enough, why do we need teaching artists?

How is a teaching artist different than a classroom teacher?

Which language or mode is best to describe what I need to say?

Which mode of expression will my audience best be able to understand?

Asking myself what does each need to know, when there are many ways to "know".

How many ways are there to say I know?

John Toth 